\title{
El periodismo y la creación literaria: una natural vinculación
}

\author{
Sonia Luz Carrillo \\ Departamento Académico de Comunicación Social
}

En Escenas de la Comedia, uno de sus estudios dantianos, Leopoldo Chiappo se refiere a la palabra como suave agitación de aire que carga la sustancia preciosa del pensar y más adelante recuerda cómo hemos inventado la manera de apresarla, hacerla silencio exterior y depositarla sobre la piedra, el papiro, la madera, el pergamino el papel y últimamente en circuitos electróni$\cos .{ }^{\prime}$ En similares términos Julio Ramón Ribeyronos dice que "el hecho material de escribir, tomado en su forma más trivial si se quiere -una receta médica, un recado- es uno de los fenómentos más enigmáticos y preciosos que puedan concebirse. ${ }^{2}$

Compartiendo la convjeción acerca de Ja-dignidad, importancia y exigencias del mensaje escrito, en las siguientes líneas nos proponemos señalar las características que permiten establecer relaciones entre escritura literaria y escritura periodística.

Vinculación que es necesario recordar en momentos en los que una actividad como la de comunicación social, no sólo es la que más espectaculares avances tecnológicos ha experimentado sino la que ha modificando substancialmente, en este fin de siglo, las nociones de tiempo y distancia, debido fundamentalmente a sus características de inmediatez, y transitoriedad.

Chiappo, Leopoldo. Escenas de la Comedia. Estudios dantianos. Lima: Universidad Cayetano HerediaConcytec, 1987, p. 27.

2. Ribeyro, Julio Ramón. Prosas apatridas aumentadas. Lima: Milla Batres, 1979.

Letras (Lima), 95-96: 69-89, 1998. 
Rapidez en la recolección de los datos, simultaneidad entre difusión y recepción, intenso fluir de informaciones a un ritmo incapaz de captarse en su totalidad. Brillos y reclamos a voz en cuello ya sea desde la radio, la televisión o los titulares de los diarios es en gran medida el paisaje urbano cotidiano. En ese caos, con esa urgencia de inmediatez y amplia cobertura, en esta cultura de la imagen -que no es Cultura de la Imaginación- la producción de textos muchas veces se descuida, al imponérsele servir a la rutina, la rigidez de unas cuantas fórmulas, o-peor aún- a la vulgaridad.

Sin embargo, paralela a la pobreza, la repetición y el desaliño de los mensajes de cierta prensa, existe en nuestro país -y en general, en nuestra lenguauna literatura sólida, de amplio reconocimiento y prestigio.

Esta doble consideración alienta la necesidad de reflexionar acerca de la dignidad del periodismo escrito, porque éste a diferencia de la información exclusivamente audiovisual -por naturaleza fugaz y sumaria- sin perder identidad ni autonomía, puede recibir los aportes de la literatura en tanto capacidad de síntesis para representar la compleja existencia humana, unida a la experimentación y renovación del lenguaje, que haga posible superar algunas de las actuales dificultades. De otro lado, también el ejercicio periodístico ha aportado -y va seguir haciéndolo- a la literatura, como lo manifestó Gabriel García Márquez: "el periodismo me ha sido muy útil en el oficio literario, me enseñó recursos para darles vạjaez la mis historids" ${ }^{3}$. Letras

La presencia de creadores liferinelli en el mejor periodismo, demuestra una larga y fecunda vinculación que es preciso considerar y revitalizar para un renovado impulso de la actividad que se ha colocado, debido a su enorme incidencia social y la incorporación de la más espectacular tecnología, en el centro mismo de la vida contemporánea. Literatura y periodismo pueden seguir aportando mutuamente sus saberes para una actividad de mayor calidad tanto ética como formal.

\section{La comunicación periodística}

La comunicación humana ha sido y es campo de incesantes estudios, sin embargo, desde inicios del presente siglo ésta se observa desde la lingüística, la

1 Chasqui. Revista Latinoamericana de Comunicación. CIESPAL. No. 52, Quito: noviembre, 1995 
antropología, la sociología, la psicología, la filosofía, y el interés que despierta excede incluso el ámbito de los estudios humanísticos. En ese sentido nos interesa iniciar esta reflexión desde sus bases.

\subsection{La Comunicación Humana}

La comunicación como proceso humano por el cual es posible intercambiar un contenido simbólico, es a grandes rasgos, la acepción con la que desde muy distintas perspectivas de análisis, podemos coincidir. Como acto también es posible definirlo en los términos clásicos de Karl Bühler, cuando, al referirse al habla, hace suya la concepción platónica del lenguaje como "un instrumento" que permite que "uno diga a otro algo sobre las cosas." ${ }^{4}$

La consideración del acto comunicativo como concreta vinculación de diversos sujetos ante la realidad, presenta la noción de intersubjetividad desarrollada posteriormente por Habermas en lo que-denomina el establecimiento de la Razón comunicativa, es decir, la capacidad de actuar y hablar de los sujetos respondiendo a las pretensiones de validez de sus actos del habla. Para Habermas, "El mundo sólo cobra objetividad por el hecho de ser reconocido y considerado como uno y el mismo por una comunidad de sujetos capaces de lenguaje y acción. El concepto abstracto del mundo es condición necesaria para que los sujetos que actuan comunicativarnante puedarizontenderse entre sí sobre lo que ocurre en el mundor'ge Puccinelli Converso»

Tal como señalara en un trabajo anterior, la presente indagación acerca de las posibilidades de los mensajes sociales, "se orienta por la consideración del acto de comunicar en tanto actuación recíproca y eficaz que permite que un mensaje sea compartido al hacerse inteligibles sus variados sentidos" ${ }^{\prime \prime}$. Vale decir, observamos el mensaje escrito en tanto tipo de texto socialmente reconocido.

Abraham Moles (1975) nos recuerda que "la palabra comunicación tiene como raíz la idea de una puesta en común y no es abusivo preguntarse si la

Bühler, Karl. "Teoria del lenguaje". Revista de Occidente. Madrid: 1961, p. 46.

Habermas, Jürgen. Teoría de la acción comumicativa. Madrid: Taurus Humanidades. Santillana, 1992, t. I. p. 30 .

* Carrillo. Sonia Luz. Conunicación Individuo y Colectividad en la obra de Julio Ramón Ribevm. Informe de Investigación. Lima: Instituto de Investigaciones Humanísticas, UNMSM. 1995. 
palabra comunidad tan extensamente empleada por los filósofos de las ciencias humanas, está vinculada a la idea de lo que las gentes tienen en común, o si bien, no sería más prudente unirla al acto de comunicación, definido éste a partir de lo que las gentes tienen en común". Líneas más adelante, en su ensayo El muro de la comunicación, señala que si bien el fenómeno es tan antiguo como el ser humano, recién empieza a estudiarse a gran escala cuando "un mediador, es decir, la técnica obliga a objetivarla [...]. Todo fenómeno nuevo aporta consigo una moda. Vivimos la moda de la comunicación y ésta es paralela a la prodigiosa expansión de los sistemas tecnológicos que la soportan"7.

En un texto clásico en el análisis de la comunicación desde el Estructural funcionalismo, el sociólogo norteamericano Harold Lasswell, (1955) enunciador del célebre paradigma ¿Quién, dice qué, a quién y con qué efecto? advierte que "no interesa tanto dividir el acto de comunicación, como contemplar el acto en su totalidad, en relación con toddo el proceso social." A partir de dos marcos de referencia: estructuray función su análisis se centra en las funciones y encuentra que la comunicación comporta tres claramente distinguibles: 1) la supervisión o vigilancia del entorno, 2) la correlación de las distintas partes de la sociedad como respuesta al entorno y 3 ) la transmisión de la herencia social de una generación a la siguiente. Para el caso de la sociedad humana, observa que hay tres categorías de especialistas actuando las funciones antes mencionadas: "Un grupo vigila el entorno político del estado como un todo, otro corre-

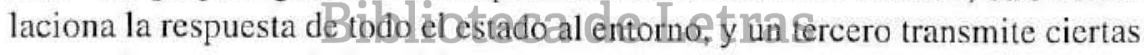
pautas de respuesta de Jer giejos a los jôvenes Diplomáticos, agregados y corresponsales extranjeros representan a quienes se especializan en el entorno. Editores, periodistas y locutores son correlatores de la respuesta de la respuesta interna. Los pedagogos, la familia y la escuela transmiten el legado social."

El pensamiento contemporáneo gira alrededor de las características que va mostrando la llamada sociedad de la comunicación. Tal como asevera Gianni Vattimo (1990): "La relación que se da entre las ciencias humanas y la sociedad de la comunicación -nuestra sociedad caracterizada por la intensificación del intercambio de informaciones y por la tendencial identificación entre acontecimiento y noticia- es mucho más estrecha y orgánica de lo que se cree".

Moles. Abraham. "El muro de la comunicación". Miguel de Moragas (ed.), Sociología de la Conumicacionn de Masas. Barcelona: Gustavo Gili, 1979, p. 93.

\& Lasswell. Harold. Estructura y función de la conunicación en la sociedad, op. cir., pp. 160 y 161. 
Insistiendo sobre esta relación el autor de La Sociedad Transparente dice: “...el intensificarse de los fenómenos comunicativos, el acentuarse de la circulación informativa, hasta llegar a la simultaneidad de la crónica televisiva en directo (y a la aldea global de MacLuhan), no representa sólo un aspecto de la modernización, sino, de algún modo el centro y el sentido mismo de este proceso"."

Un trabajo clásico sobre los diferentes modos de comunicación de los seres humanos es el de Charles W. Morris (1938) Fundamentos de la teoria de los signos. En él el autor propone tres dimensiones y niveles de la semiosis: "En términos de los tres correlatos (vehículo sígnico, designatum, intérprete) de la relación triádica de semiosis, puede abstraerse -para convertirse en objeto de estudio- una serie de relaciones diádicas. Morris hace derivar relaciones que denomina: dimensión semántica, dimensión sintáctica y dimensión pragmática. ${ }^{10}$

A partir de este esquema y en uso de la terminología propuesta por Morris, son muchos los trabajos que han ineidido en el área pragmática, como el del estudioso español Pedro Costa que plantea la siguiente clasificación: "El estudio de la comunicación humana es susceptible de ser dividido en una área sintáctica, en otra semántica y en otra de nivel pragmático. La primera se ocuparía de los problemas que plantea la transmisión de información. La semántica estudiaría primordialmente los significados y los códigos. La pragmática, por su parte, se ocuparía bassicamentedeh estudiō de lacomunicación en cuanto afecta a la conducta" "Jorge Puccinelli Converso»

Y es en esta área pragmática en la que se ubica la observación en torno al mensaje cuando éste opera en términos periodísticos, es decir con las nociones inherentes de Actualidad, periodicidad y amplia divulgación.

\subsection{El Mensaje Periodístico}

Un mensaje que tiene de relato, de descripción y argumentación, mediante el cual se cuentan hechos recientes, capaces de interesar a públicos di-

\footnotetext{
"Vattimo. Gianni. La Sociedad Transparente. Barcelona: Paidós. 1990. pp. 89 ss.

10. Morris. Charles. Fundamentos de la Teoria de los signos. Univiversidad de Chicago, 1938. Edición española. Barcelona: Paidós, 1985, p. 120.

1 Costa. Pedro. Hipótesis para una metodología de la comunicación. Volumen colectivo: Comunicación y condición humana. Ponencias del I Congreso Nacional de Comunicación Humana y Ecología. Barcelona 1972. pp. $145 \mathrm{ss}$.
} 
versos, es una definición con la que muchos podemos coincidir. Pero es importante colocar este mensaje en el contexto de la amplia esfera de la comunicación social.

Como es evidente, el mensaje a través de los medios masivos presenta múltiples formas y cumple muy variados fines. En torno a éstos Martínez Albertos, en su obra ya citada, establece una subdivisión interesante:

"1. La información de actualidad o Periodismo, tiene como fin específico la difusión objetiva de hechos a través de la información, la interpretación y el comentario de los acontecimientos que son noticia.

2. La Propaganda tiene como fin específico la difusión de ideas o doctrinas por la vía de la sugestión emotiva que se dirige a lograr cierto grado de coacción sobre los receptores.

3. El Anuncio o Publicidad comercial tiene como fin específico la difusión de una mercadería entre los consumidores de un régimen de mercado competitivo.

4. Las Relaciones Públicas tienen como fin específico la difusión parcial de hechos e ideas relacionados con una actividad o servicio, con el objeto de crear un clima de cordialidad pública a favor de ese servicio"12.

En torno al primer tipo de mensaje - y tal vez el más rápidamente identificable- el profesor F.'Fattorello cifado pot Martỉnez Albertos ha propuesto un cuadro de rasgos particulares: "Los fines de la información de actualidad son específicamente informativos u orientadores [...] está asentada tanto desde el punto de vista técnico como científico, sobre una concreta y precisa teoría de la noticia". Respecto a los aspectos deontológicos y actitudinales de los comunicadores o periodistas Fatorello dice "la objetividad debe ser entendida como una meta que hay que conseguir en el ejercicio profesional. Esta presunción deontológica puede ser mejor valorada si en lugar de objetividad periodística hablamos de honestidad intelectual del periodista."

Como quiera que la objetividad es uno de los rasgos que con mayor insistencia se reclama, especialmente para el ejercicio de la información contingen-

12 Martínez Albertos. "El Periodismo como información de actualidad", Curso General de Redacción Periodistica. Madrid: Paraninfo, 1993, pp, 41 ss. 
te, es interesante anotar lo que Fattorello afirma en torno a un punto que entraña aspectos profesionales, técnicos y éticos: "La honestidad intelectual, requisito indispensable para que se dé una verdadera información de actualidad o Periodismo, debe quedar efectivamente reflejada en el sincero respeto que los promotores del proceso tengan por la libertad de respuesta de los sujetos receptores: libertad de respuesta para adherirse o para rechazar los contenidos de polarización que se ofrecen a su consideración a través de los mass-media."13

En la misma línea, Emil Dovifat (1960) al glosar las tres características del mensaje periodístico " Actualidad (las últimas noticias), periodicidad (periodos cortos y regulares) y genericidad (la más amplia circulación)" advierte que estas tareas se unifican gracias a tres diferentes soportes: "El equipo intelectual o espiritual (los hombres y mujeres redactores de la empresa periodística), la base económica (la empresa editorial) y el equipamiento técnico necesario".

Acerca de las particularidades de la tarea de transmitir el mensaje a través de grandes medios y las exigencias profesionales y deontológicas que esto lleva, el maestro alemán señala": En un periódico actúan tres fuerzas inseparables: las espirituales, las económicas y las técnicas. Ninguna puede prescindir de las otras. Pero la tendencia a que domine la espiritual es la concepción de todo periodista con sentido de responsabilidad."14

\subsection{El estilo periodístico}

\section{Biblioteca de Letras «Jorge Puccinelli Converso»}

La comunicación periodística vista en su dimensión de comunicación humana potenciada en extremo por la aplicación de la más alta tecnología, constituye un proceso de interrelación de individuos y grupos en una sociedad, que se concreta en forma de un tipo de mensaje, una forma de organización de discurso al que -en términos generales- se le exige ser claro, directo, breve y preciso.

En torno al tipo de mensaje con finalidad periodística se vienen realizando estudios tanto desde la lingüística como de la investigación en comunicacio-

\footnotetext{
" Fattorello. Francesco. Introducción a la Técnica Social de la Información. citado por Martínez, op, cit.. pp. 42-43.

14 Dovifat, Emil. Periodismo. México: Uteha. 1960, pp. 13 ss.
} 
nes. Se trata de hallar los rasgos típicos de un mensaje dirigido al mayor número de receptores, haciendo accesible sus contenidos a personas de experiencias socio-culturales heterogéneas.

Susana González Reyna (1991) nos dice que "En el periodismo se combinan motivaciones sociológicas y lingüísticas para la elaboración de los mensajes, pues el periodista es un intérprete del acontecer social, quien en su discurso construye la realidad". También nos recuerda que: "El discurso es una estructura formal, una organización lógica de signos que tiene una significación precisa. El hombre usa al discurso para comprender primero, y transmitir después la realidad. El periodista se vale del discurso para informar los sucesos; describir las situaciones, los personajes y los escenarios; relatar los acontecimientos; evaluar los hechos y comentar las noticias." ${ }^{\text {. }}$.

Describir, relatar, exponer y argumentar son precisamente las distintas maneras de usar el lenguaje para comunicar algo, operaciones discursivas básicas que en el caso del mensaje periodístico requieren un ordenamiento conforme a un código preestablecjio y ampliamente compartido. De esta forma se produce la construcción de sentido.

En su clásico Curso de Redacción, Gonzalo Martín Vivaldi introduce el tema de La información y la noticia, con una serie de conceptos útiles de releer. Dice, por ejemplo: "Expuestas ya las líneas generales del arte de escribir y estudiadas algunas de las tecnicas mas necesarias para nuestra disciplina, abrimos un apartado especial acerca de la técnica de Pa inforsonación. En este campo literario -continúa explicando- el arte de escribir, la técnica, se circunscribe más. Las reglas son más fijas, dentro de la natural flexibilidad y elasticidad de nuestra disciplina."

Más adelante, refiere: "se notará en las páginas que siguen una constante referencia a la técnica periodística. Nada más lógico. La técnica informativa ha adquirido rango de modelo en el periodismo". Luego hace una interesante aseveración: "El periódico es, ante todo y sobre todo, información: desde el artículo de fondo hasta el más modesto anuncio, todo responde a la más precisa técnica informativa [...] todo ello dirigido a un gran publico, a un tipo medio de lector, al que se pretende decir todo lo que de interés sucede en el mundo, del modo más correcto, claro y breve posible" ${ }^{\text {". }}$. Y al referirse a las condiciones in-

\footnotetext{
15 González Reyna, Susana. Periodismo de opinión y discurso. México: Trillas, 1991, p. 5.

16. Martínez Albertos. J. Curso de redacción periodística. Madrid: Paraninfo, 1993.
} 
dispensables en una noticia bien redactada señalará los requisitos del mensaje informativo: veracidad, exactitud, interés, claridad, brevedad, rapidez e integridad.

Emil Dovifat reclamaría al discurso informativo "concisión, claridad y una construcción que capte la atención", mientras el profesor español Lázaro Carreter señala como distintivo de todo buen escrito, sea cual fuere la naturaleza de su difusión: naturalidad, claridad y concisión. En su libro Curso General de Redacción Periodística, Martínez Albertos cita al profesor norteamericano Neale Cople, cuando éste dice: "la claridad es lo más importante en el estilo periodístico [...]. Son muy convincentes también el ritmo y el colorido. Una buena introducción es excelente ayuda".

Martínez Albertos cita también a Cople y según el maestro español, en el libro del norteamericano aparecen las notas que definen el estilo informativo: "sencillez, claridad, simplicidad -sìn que ésta signifique rebajamiento de las cuestiones en sí- densidad de datos informativos, concisión-aunque tampoco hay que abusar de frases breves- cambio de ritmo narrativo mediante la alternativa de frases cortas con frases largas, referencias personales (es decir, hábil utilización de los pronombres personales, que pueden crear una cierta sensación de diálogo)." Para Cople, eł dominio de un buen estilo depende más de un conocimiento profundo del idiona que de la habilidad para aplicar fórmulas de cómo escribir textos periodísticos. La docencia universitaria en esta disciplina, personalmente, me ha servido paraconstatar laverdad de esta consideración. Las "recetas" para la elaberacón de uninexto pocovecytan cuando el redactor o redactora no tiene aún el cultivo personal necesario que le permita asistir con sensibilidad y transmitir - por ello- con eficacia, los acontecimientos del mundo contemporáneo.

"La palabra técnica -dice Neale Cople-se presta a confusiones. Saber escribir un reportaje en forma de pirámide invertida, cosa que no es estilo, puede aprenderse en seis meses en la sala de redacción o en el aula. Es simplemente una fórmula. El estilo es hijo del saber; de la experiencia, del buen juicio, del gusto y de la habilidad disciplinada. Todo ello unido al pensamiento. Mediante el pensamiento, y no mediante fórmulas, se logra la profundidad. Es algo que no se aprende en seis meses o en seis años, pues es algo que ya estamos desarrollando y que seguirá en desarrollo hasta el momento en que nos retiremos, siempre y cuando escribamos con la mente y no con fórmulas"17.

17 Colple, Neale, en Martínez Albertos. Op. cit. p. 221. 


\subsection{El Periodismo escrito}

Espacios y emisoras radiales dedicados a la información, noticieros televisivos a diferentes horas del día, canales vía cable especializados en noticias, podría hacer pensar que la prensa, el más antiguo medio, ha perdido vigencia. No sólo no es así, sino que ella aparte de haber dado origen a muchas de las técnicas de presentación del mensaje, marcó con su actividad la terminología referida a información. En la actualidad, por ejemplo, todavía se mencionan las agencias de noticias como Agencias de Prensa (UPI, AP, AFP, etc.); igualmente, al hablar de una instancia de comunicación pública en alguna entidad, se señala, Oficina de Prensa, o también Comunicado de Prensa, Nota de Prensa, y los periodistas de todos los medios siguen siendo llamados hombres y mujeres de Prensa mientras los personajes públicos brindan "declaraciones a la prensa" frente a las cámaras de televisión. De otro lado cuando se quiere poner de relieve la influencia del periodismo en una sociedad, se habla de la Prensa como Cuarto Poder. Y cuando las libertades se hallan amenazadas, diversas voces reclaman Libertad de Prensa. Sin embargo, son innegables los cambios producidos en la prensa a tenor de los espacios que fueron conquistando otros medios, los distintos lenguajes que se experimentaron -creando nuevas exigencias y necesidades en los públicos- que motivó importantes cambios en la prensa. Es más notorio sea tal vez el de łă especialización temática que atiende a distintos segmentos de públiço.

\section{Biblioteca de Letras}

De otro lado, cojperartiende criteriosnoticienses, básicos, tanto la prensa como los medios audiovisuales fueron evolucionando, influyéndose mutuamente pero también construyendo cada uno una manera de codificar sus mensajes. Construyendo cada medio su particular lenguaje.

\subsubsection{Particularidad del periodismo escrito}

Para comprender la naturaleza del periodismo escrito es indispensable recordar que "Un periódico es una empresa que tiene como función esencial transformar los acontecimientos en noticias. Una empresa industrial que además de los periodistas necesita de la colaboración de numerosos empleados y obreros", como dice Philippe Gaillard $(1972)^{18}$. Y en esta empresa se fabrica

\footnotetext{
18 Gaillard. Philippe. Técnica del Periodismo. Barcelona: Oikos-Tau Ediciones, 1972, pp. 15 ss.
} 
un producto muy especial: un conjunto de contenidos simbólicos, esperados por el público lector, consumido ávidamente en las siguientes horas de su producción y luego arrojado al tacho de desperdicios o acumulado para ser entregado a alguna institución de bien común, ahora convertido sólo en papel, en pasado, como si de pronto se hubieran borrado los caracteres que lo hicieron apetecible. Salvo que contenga uno que otro material que soporte el paso de las horas, algún material que venza el destino ineludible del mensaje periodístico: su perecibilidad.

En este punto también es útil recordar que la información periodística nace históricamente vinculada a un fenómeno de prestigio social en la cultura occidental: la posibilidad de la lectura, unida a la capacidad de fabricar papel y las posibilidades técnicas para lograr imprimir en éste tantos ejemplares de un texto como fuera necesario. Como sabemos, un acontecimiento de enorme repercusión es la aparición y expansión de la imprenta que hizo posible no sólo la difusión masiva de hechos ocuerridos sino también la difusión de juicios subjetivos sobre estos hechos.

Precisamente por estas funciones de informar y orientar, muchos discuten hoy sobre otras funciones (sociales y culturales) que cumple el periodismo escrito. Al respecto Martínez Albertos hace conocer su posición basada en la diferencia establecida entre la información contingente en la que el periodista es el emisor, y la informaçóniló contingente en la gue el emisor es un educador o cualquier otro especiallista A partir de esta distinción, señala: "Me inclino por la idea de que el periódico por medio de sus diferentes variantes de papeles impresos: el diario, el semanario, la revista gráfica, la revista de pensamiento, la revista literaria etc. -es más un producto cultural que refleja los niveles de desarrollo científico y técnico de una sociedad que un instrumento para la cultura y la educación de los pueblos."

La prensa (diarios, semanarios, revistas), es uno de los varios canales por los que se opera ese vasto fenómeno contemporáneo que es la comunicación social. Sólo a ella se denomina periodismo escrito, pero la verdad indica que también las noticias de los medios audiovisuales, previamente a su difusión. son también materia textual, texto.

Sin embargo, lo que distingue al mensaje sea cual fuere el canal utilizado, son las distintas modalidades expresivas. En el caso de la prensa la realidad es representada a través de: 1) Series visuales lingüísticas; 2) series visuales para-lingüísticas y 3 ) series visuales no-lingüísticas. 
En las series visuales lingüísticas se incluyen aquellos textos publicados y que aparecen desarrollados y expuestos siguiendo los requerimientos de una forma lineal y discursiva. A tenor de su contenido los textos serán informativos, interpretativos u opinativos; todos ellos enmarcados en lo que llamamos materiales de actualidad. Pero también encontramos texto de finalidad comercial, propaganda ideológica, relaciones públicas. Vale decir, cualquier tipo de texto que intenta un grado de comunicación cognitiva ingresa a esta serie.

En la serie para-lingiüística, un conjunto de variaciones cumplen -en los medios impresos masivos-las mismas funciones que cuando se producen estas variaciones en la comunicación interpersonal y el lenguaje oral: El tamaño de los titulares y la tipografía usada, la disposición espacial de los textos y otros elementos, el uso de las comillas, el uso de cursiva o negrita, son rápidamente identificables con el tono de voz, el volumen del timbre etc. Las series visuales no-lingüísticas las conforman las imágenes fotográficas, los dibujos, el color, las variaciones de papel, entre otros elementos.

De otro lado, el lenguaje periodísticoen los medios escritos es un lenguaje no-literal, es un lenguaje fuertemente connotativo, su decodificación depende del contexto, y, al menos en términos ideales, debemos ubicarlo en el nivel coloquial de los sectores cultos de una población. El periodista, en tanto emisor, busca primordialmente transmitir un mensaje en condiciones óptimas de rapidez y eficacia comunteâliyä: Es-deein unaconstrueción que capture el interés del lector:

\section{"Jorge Puccinelli Converso»}

Sobre este tercer punto el padre Emil Gabel, durante varios años Presidente de la Unión Católica Internacional de Prensa UCIP, menciona como "leyes psicológicas de la información periodística": la esquematización, la dramatización y la variación cíclica del interés. Veamos que comportan estas leyes:

La esquematización, consiste en reducir la complejidad de los datos informativos a un cuadro sencillo y comprensible gracias al cual, pueda ser ésta asimilada en una lectura rápida e incluso precipitada.

La dramatización, llamada también la "puesta en escena de una información" está ligada al concepto de interés humano, descansa en los recursos del teatro y busca implicar directamente al lector. Su abuso -lamentablemente, $\tan$ frecuente en la actualidad, con el sensacionalismo exacerbado- hace que se pierdan de vista los límites de la sobriedad. Peligrosamente, además, consigue que mucho de lo que acontece tenga un barniz de espectacularidad y superficialidad. 
La variación cíclica del interés es un fenómeno psicológico que obliga a cambiar de enfoque expositivo si quiere seguir atrayendo a su público. Un hecho, por más importancia que tenga o parezca tener, no puede ser publicado durante un tiempo indefinido. Si el diario o la revista ha optado por realizar una campaña deberá en cada edición mostrar nuevos ángulos del tema que mantengan abierta la atención de su público. Este criterio está íntimamente ligado al carácter transitorio del mensaje periodístico.

De otro lado, si bien es importante tener en cuenta que el lector normal de un periódico es un lector no especializado, una recomendación valiosa que recogemos de grandes maestros del periodismo estriba en el respeto del periodista a sus lectores, el imperativo de no subestimar al lector.

\section{5 Normas y cautelas en el Periodismo Escrito}

Tanto el periodismo escrito como el audiovisual, vive a la caza de respuestas a las preguntas típicas. Las célebres ¿Qué? ¿Quién? ¿Cuándo? ¿Dónde? ¿Cómo? y ¿Por qué? Respuestas que redactadas en forma sumaria dan como resultado el lead o lid, primer párrafo de la información en la estructura de Pirámide Invertida, llamada así debido a la importancia de ese primer párrafo respecto del cuerpo de la información, es decir, respecto de los siguientes acápites en los que se amplial los detatles concentradosen el encabezamiento.

Respecto a la elaboración del texto se propone un conjunto de reglas prácticas: Los verbos deber usarse, siempre que sea posible en forma activa. El tiempo presente es útil para dar vigor y sensación de actualidad a las narraciones. Especial vigilancia merecen los gerundios; evitar los vocablos preconcebidamente "poéticos"; evitar el exceso de comas, lo que se consigue al construir la frase en orden lógico gramatical. Se recomienda asimismo: Adjetivar con cautela; en caso de duda preferir la oración sustantiva; usar cuidadosamente imágenes y metáforas para no dar la sensación de afectación y cursilería. Se aconseja también evitar entrecomillar y, en general, usar recursos que puedan interpretarse como adoctrinamiento al lector. El yo del periodista -en los trabajos informativos- merece una atención particular. Puede usarse con cautela en algunas crónicas o reportajes. Los puntos de vista del periodista siempre son comentarios, juicios subjetivos. 


\subsection{El Relato Periodístico}

Antes de ingresar al relato periodístico, revisemos el concepto relatar o narrar en términos generales. El llamado discurso de acción, el concepto se lo debemos a Teun Van Dijk (1976), se define como "el tipo de discurso que trata de acciones humanas". Desde este punto de vista, la narración o relato es la forma de representación de una acción natural. Esto es válido también para otros textos. En primer lugar, es útil recordar que Aristóteles define literatura, como "imitación de una acción". Y dentro de la literatura dos formas de imitación: la narración y el teatro (en tanto representación). Igualmente, es necesario mencionar la existencia de la narración más allá de la literatura, lo que Van Dijk llama narraciones naturales referidas a las circunstancias cotidianas de la conversación.

Otra manifestación de los discursos de acción se da en los diferentes tipos de textos informativos (noticia, crónica, reportaje, etc.) puesto que tratan esencialmente de acciones humanas. Aquí también se puede distinguir entre narración y representación

En torno a este punto en su célebre Poética, Aristóteles distingue las dos maneras de imitar las acciones. Primero, mediante el discurso, narrándolas. Y segundo haciendo hablar a los imitados cemo operantes y actuantes, por representación, ya se trate de un monólogo o un diálogo. Lo que es sumamente interesante para el tema materia de este estudio y la especialidad desde la que se aborda, es que estas dósformas fúcione enumciadaserentazón de la existencia de una mayor o menor proximidad a la vida, según se dé una mayor o menor impresión de realidad.

En el caso de Comunicación Social, las noticias a través de la prensa o la radio habitualmente serán narradas, pero también pueden ser representadas (citas textuales, encuestas, entrevistas etc.), mientras las emitidas por televisión, tendrán más similitud con lo que Aristóteles distinguía como los elementos de representación teatral: Discurso, escenografia y música. Esto se hace aún más evidente en los reportajes y en las películas. Mientras tanto, en la publicidad se narra historias o las representa mediante personajes que hablan y actúan en relación a un producto e incluso convierten el producto en un personaje más de la representación.

En el caso del relato en el mensaje periodístico, debemos mencionar la existencia de los géneros considerando las actitudes del emisor. Así tenemos: a) 
Actitud informativa (nota informativa, crónica, entrevista y reportaje); b) Actitud interpretativa (Informes, reportajes ampliados, especiales, etc.); c) Actitud opinativa (Columna editorial, artículos de opinión, comentarios y columnas especializadas etc.)

\subsection{Relato y Géneros Periodísticos}

El relato, en mayor o menor medida aparece en todas las especies y géneros periodísticos. En el caso de la Nota Informativa, si bien la forma básica del discurso es la exposición, responder a las preguntas típicas del periodismo implica un breve relato de lo acontecido. Mientras tanto, la Crónica es esencialmente narrativa, con fuerte apoyo de la descripción: Se recurre a la forma discursiva del relato para destacar la trascendencia de lo acontecido y la descripción para dar al lector la impresión de ser testigo directo del acontecimiento. La entrevista es un género descriptivo-narrativo. Se apoya en el relato para dar mayor interés al mensaje. Tiene de exposición cuando el objeto es transmitir información y se vale de la descripción para-indicar las características del entrevistado y del ambiente en el que se prođujo la conversación.

El reportaje se propone ebrelato de aspectos desconocidos de un asunto ya informado y por ello tiene forma discursiva narrativa con apoyo en la descripción (notas de "color", y presencia de "voces", en el argot periodístico). Da lugar en ciertas ocasiones a que efperiodista refieje sus impresiones acerca de los hechos, y por ello tainbión tiencech refüerzondeelasargumentación o exposición.

Dentro de los géneros de opinión podemos además hallar con cierta frecuencia fragmentos de relato, sobre todo cuando se intenta situar las ocasiones y circunstancias en las que se produce el fenómeno o hecho ante el cual se tiene una posición, una opinión.

Vemos así que el relato o narración es columna vertebral del mensaje periodístico. Tanto que Mar de Fontcuberta en su obra ya citada, afirma que «[en el periodismo] el texto narrativo puede bastarse a sí mismo; en cambio el descriptivo y el argumentativo, tienen que referirse a una secuencia que pueda narrarse. Según esta división, en los aspectos narrativos predominan las respuestas a qué ha sucedido, quién ha sido el protagonista y cuándo ha sucedido; los aspectos descriptivos apoyan las respuestas a qué ha sucedido, quién ha sido el protagonista, cómo y dónde ha sucedido; y el discurso argumentativo será imprescindible en la explicación por qué ha sucedido. 


\section{Creación literaria y mensaje periodístico}

Ya sea para negar todo vínculo como para señalar cuánto le debe uno a otro, desde muy antiguo los conceptos de creación literaria y mensaje periodístico aparecen unidos en muy diversos estudios, tanto literarios como de comunicaciones. Sin olvidar que el mensaje literario es semánticamente autónomo, genera "su" realidad - de la que sólo se espera que sea verosímil-mientras el mensaje periodístico tiene la exigencia de la veracidad, existe sin embargo en la producción de ambos tipos de discurso, un nexo fundamental: en el desorden de la vida crean por selección y organización de datos, un orden, el retrato simbólico de una situación. Y lo hacen mediante las formas discursivas básicas de descripción, narración, argumentación y transcripción de la oralidad.

Como recuerda Octavio Aguilera (1992) las relaciones entre literatura y periodismo han conocido todas las gradaciones posibles desde la más absoluta identificación hasta la polémica ardorosa, cita a José Acosta Montoro, defensor de la identificación quien arguye que "son inseparables como la rama de un tronco"19. Para Martínez Albertos, se trata de ejercicios que se dan en ámbitos diferentes, con objetivos distintos; otros prefieren ubicar al periodismo como secuela de la literatura, mientras señalan que si bien se trata de dos ámbitos de trabajo diferentes siempre han tenido y tendrán muchos puntos de contacto.

\section{Biblioteca de Letras}

\subsection{Rápida mirada a una antigua y persistente vinculación}

De hecho, nadie puede desconocer que el origen del periodismo se entronca con la literatura. No sólo poetas o narradores han escrito en los diarios más importantes, sino que diversos intelectuales han usado este medio. Tal como lo expresa Rafael Roncagliolo (1996) analizando las autorrepresentaciones del papel del periodista que se han venido dando en América Latina a través de distintas etapas, la primera corresponde al periodista como intelectual. Según el autor, esta imagen del periodista es la dominante en el caso peruano entre 1584, al establecerse la imprenta en Lima, hasta aproximadamente 1821 en los albores de la Emancipación, pasando por hitos muy importantes como son: la aparición de la Gaceta de Lima, en 1715; la fundación de El diario de

19 Aguilera. Octavio. La Literatura en el Periodismo. Madrid: Paraninfo, 1992, p. 29. 
Lima, en 1790, el Mercurio Peruano, en 1791, entre muchos otros valiosos órganos de prensa que vehiculizaron las ideas de libertad política ${ }^{20}$.

Al respecto Mar de Fontcuberta (1993) afirma "La diferencia entre periodismo y literatura es que el primero tiene, por lo menos en teoría, la misión de explicar hechos sucedidos en la realidad, y la literatura, como norma, expone hechos de ficción"'21. Habría que mencionar junto con Fontcuberta que la dosis de ficción es el elemento tal vez más significativo en esta distinción.

Existen textos periodísticos elaborados con aportes de la novelística (en el caso del Perú es notable la obra periodístico-literaria de Guillermo Thorndikee), y grandes narradores que han llevado al libro los temas directamente aportados por la realidad. En América Latina, tenemos el caso de Gabriel García Márquez con su Noticia de un secuestro, como también lo es de alguna manera El pez en el agua, mezcla de biografía, reportaje y novela de Mario Vargas Llosa.

En el ámbito internacional, es preciso mencionar a una serie de excelentes escritores y no menos importantes reporteros que han puesto de manifiesto en innumerables ocasiones qué ocurre cuando la timaginación se pone al servicio de la actividad en comunicación social. El periodismo escrito inglés y norteamericano presenta los nombres de Charles Dickens, Oscar Wilde, Mark Twain, y Joseph Pulitzer, entre otros. Mención aparte merecen John Reed

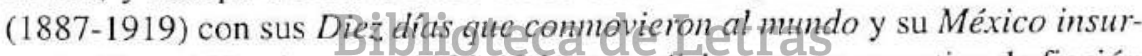
gente; Ernest Hemingway (1899-1961) tan célebre por su narrativa de ficción como por su labor de corresponsal y reportero; y George" Orwell (1903-1950). Sus reportajes, despachos como corresponsales, crónicas de acontecimientos o de viajes, entrevistas etc. abrieron el camino a otros periodistas que, décadas después, en los años 60, harían nacer el concepto de Nuevo Periodismo. Liderados por el gran periodista Truman Capote (a sangre fría), un grupo de jóvenes llevan a la práctica una nueva forma de narrar los acontecimientos ${ }^{22}$.

20 Roncagliolo, Rafael, "El Periodista en la quinta revolución cultural". Chasqui, No. 54, junio, Lima, 1996. pp. 4 ss.

21 Fontcuberta, Mar de. La Noticia. Pistas para percibir el mutodo. Barcelona: Paidós. 1993, pp. 94 ss.

22 En su libro El Nuevo Periodismo. Michael Johnson. Buenos Aires: Troquel, 1975, pp. 82-83, señala que "Capote desplazó su energía creativa de la ficción a los relatos novelados sobre un suceso real [...] es notable su sentido del lugar, fundamental para su estilo y la verdad del periodismo [...] ha seleccionado detalles realistas, fiel a la práctica periodística más tradicional [...]. En armonía con los propósitos periodísticos, el diálogo es totalmente verosímil . derivados de conversaciones y recuerdos de la experiencia humana [...] los personajes están bellamente logrados [...]. Capote permite al lector descubrir sus personajes exactamente como él los descubrió como personas". 
Entre ellos podemos citar a Norman Mailer, Ton Wolfe, Irving Wallace y Susan Sontang. En el periodismo español, se puede citar a Francisco Umbral, Rosa Monteo, Juan Luis Cebrián, etc. El periodismo italiano tiene a Oriana Fallaci, polémica reportera y entrevistadora.

\subsection{Literatura y periodismo en el Perí.}

En nuestro país, cuando Don Jaime Bausate y Mesa publica el $1^{\circ}$ de octubre de 1790 su célebre Diario de Lima, se inicia una estrecha y larga vinculación de literatura y periodismo vigente hasta nuestros días. Sobre la reacción que este diario "curioso, erudito, económico y comercial " produjo, da cuenta Luis Alberto Sánchez (1928): "En 1791, sale el Mercurio Peruano, periódico destinado a transformar la mentalidad del Perú". Sánchez anota que en esos momentos se vivía un renovado interés por el arte escénico y menciona cómo el tercer número del periódico de la Sociedad Amantes del País -académicos ilustrados- comenta "el principal [espectáculo] es el de la comedia. Sus decorados son regulares, los representantes no son malos. Entre ellos hay alguno que pudiere lucir en Madrid mismo". Ha nacido el periodismo cultural, la reseña teatral. Párrafos más adelante, Sánchez hace una afirmación interesante: “...la más eminente entre las actividades literarias de aquella época fue el periodismo." ${ }^{23}$

\section{Biblioteca de Letras}

En torno a el Mercurzo Pencaio gllå Cabondelperiodismo en la determinación de la idea de patria Raúl Porras Barrenechea, señala: "El Diario de Lima podrá haber arrebatado por algunos meses al círculo de hombres ilustres que formó la Sociedad Amantes del País para escribir El Mercurio Peruano la primacía en la iniciativa y en el tiempo dentro del periodismo sudamericano, pero no podrá arrebatarle la preferencia en la admiración. El Mercurio Peruano realizó una doble e histórica labor. Al proponerse sus redactores el Perú como objeto de estudio en todos los órdenes del saber, afirmaron el sentimiento patriótico que había de impulsar la revolución. Si no le bastara este mérito de su evidente dirección nacionalista, tiene el Mercurio, sobreabundantes prestigios para merecer el primer puesto entre nuestras publicaciones de ayer y de hoy. Ninguna ha alcanzado más alto renombre científico ni esparcido mejor el nombre peruano. Sus noticias del Perú desconocido y fabuloso, de la geografía y de

:3 Sánchez. Luis Alberto. La Literatura Pernana. 6a. ed. Lima: EMI S. A., 1989. pp. 954 y 955 
la historia, sus profundas observaciones sociales, su estudio del medio, sus fecundas iniciativas, su constante anhelo de mejoramiento, tuvieron el poderoso atractivo de la originalidad." 24

Posteriormente, poetas, narradores, ensayistas, han continuado enriqueciendo el periodismo peruano. Imposible dejar de citar a los diaristas de la primera etapa de la República como Felipe Pardo y Aliaga y Manuel A. Segura, los periodistas de la generación romántica entre los que destaca indudablemente Ricardo Palma; las notas de González Prada, de quien Augusto Tamayo Vargas (1993) recuerda «el diario El Nacional ofrece sus primeras lecciones duras de crítica política y social, y se une a la tarea de algunos prominentes hombres de letras del "Club Literario", que estudia las nuevas manifestaciones filosóficas y la crisis del romanticismo" "25; la intensa actividad periodística de Colinda Matto de Turner -directora del importante semanario El Perú ilustrado- y Mercedes Cabello, articulistade El Correo del Perú y de El Perú ilustrado; las crónicas de los modernistas, entre los que habría que resaltar a Enrique Carrillo "Cabotín" de quien Antonio González Montes (1996) dice: "Escritor polifacético, elegante y original, suele gozar de mayor prestigio como periodista (uno de los mejores cronistas) que como novelista y cuentista"; luego, la obra de José Carlos Mariátegui quien ho sólo se inicia en los talleres del diario La Prensa donde publica sus primeras crónicas sino que se convierte en promotor de publicaciones de enorme trascendencia en la vida nacional como Amauta, esa irrepetible experienclaeditotia,CQ Razón y tabas por citar sólo algunas publicaciones periódicasorge Puccinelli Converso»

Es necesario mencionar también a Abraham Valedomar, de quien González Montes dice: "magnífico y creativo periodista". A César Vallejo periodista, permanente articulista de diversos medios entre los que se cuenta el diario $\mathrm{El}$ Comercio y autor también de un importante reportaje, Rusia 1931. Reportaje al pie del Kremlin. . Luis Alberto Sánchez comentarista y articulista de extendida presencia, etc. De otro lado, conscientes del carácter-por definición-efímero del periodismo, algunos periodistas han llevado al libro sus mejores trabajos.

Reportajes de ambiente, épocas o personajes, han quedado como testimonio de la calidad y permanencia de sus autores, baste citar en las últimas déca-

\footnotetext{
:4 Porras Barrenechea, Raúl. "130 años de periódicos". Mundial, julio 1921. Reproducido en Talleres de Comusicución. Lima: Fimart, s.f., pp. 45-46.

* Tamayo Vargas. Augusto. Literattra peruana. Lima: PeisA, 1993, tomo II, p. 581
} 
das, a Guillermo Thorndike, director de varios diarios de gran éxito a la vez que autor de reportajes novelados (No, mi general, Abisa a los compañeros, El caso Banchero, Los apachurrantes años cincuenta, Maestra vida, etc. por citar sólo algunos). ${ }^{26}$

\subsection{Ventajas y exigencias del Periodismo Escrito.}

Frecuentemente se señala que ante el acontecimiento convertido en Información Periodística, la radio anuncia, la televisión presenta y el periódico explica, interpreta. Frente a las características de inmediatez, espectacularidad y extensión de la cobertura, la prensa -sin perder de vista la necesidad de competir-mantiene la ventaja comparativa de la reflexión. No llega tan rápido, pero puede y debe consignar mejores y más sólidos datos. Su cobertura tiene límites, pero su permanencia y posibilidad de mayor reflexión tanto de parte de los emisores como del público lector la convietten en una alternativa sumamente útil en momentos en que una enorme masa informativa presiona a los demás medios a dar una información cada véz más espectacular, breve y superficial. A propósito de este punto, el narrador peruano Mario Vargas Llosa, con ocasión de recibir el Premio de la Paz de los Libreros y Editores Alemanes (1996) expuso: "La información audiovisual, fugaz, transeúnte, llamativa, superficial, nos hace ver la historia como ficción, distanciándonos de ella mediante el ocultamiento de sus causas, engranajes, contextos y desarrollos de esos sucesos que nos presenta de mođo tan vívido . Lmeas atrás nos había descrito con gran maestría: "La fantástica acuidad y versatilidad con que la información nos traslada hoy a los escenarios de la acción en los cinco continentes, ha conseguido convertir al televidente en un mero espectador, y al mundo en un vasto teatro, o mejor, en una película en un reality show enormemente entretenido, sin duda, donde a veces nos invaden los marcianos, se revelan intimidades picantes de las personas, y, a veces, se descubren las tumbas colectivas de los bosnios sacrificados de Sebrenica, los mutilados de Afganistán, caen cohetes sobre Bagdad o lucen sus esqueletos y sus ojos agónicos los niños de Ruanda". ${ }^{27}$

26. Entre los poetas y narradores de las últimas cinco décadas, son tantos los que han realizado y realizan diversas labores dentro de los medios de comunicación social -incluyendo a Mario Vargas Llosa y Alejando Romualdo, entre otros notables escritores- que se torna imposible consignar todos los nombres.

27 Vargas Llosa, Mario, "Dinosaurios en tiempos difíciles". Conferencia en la Feria del Libro de Francfort. 6 de octubre de 1996, con ocasión de recibir el Premio de la Paz de los Libreros y Editores alemanes. En Lima. ha sido publicado por el Boletín $N^{\circ} 22$ del Instituto del Ciudadano, noviembre de 1996. 
Fácilmente se concluye la enorme necesidad de un renovado impulso de parte del periodismo, de la palabra escrita, en general. Vargas Llosa lo dice con respecto a la literatura, pero el reto está lanzado también para el periodismo.

Pero, ¿está el periodismo escrito en condiciones de contenido y forma para hacer frente al reto? Lamentablemente, la prensa no escapa a los problemas anotados por nuestro novelista. A los problemas de concepción noticiosa se suma la rigidez de los esquemas en los que se encuentra muchas veces aherrojada. Frases manidas, descuido y maltrato idiomático, repetición de fórmulas, vulgaridad llevada a extremos agresores, un conjunto de rasgos que hoy presenta el mensaje escrito en gran cantidad de periódicos.

Precisamente las reflexiones de este trabajo quieren colaborar en la búsqueda de alternativas para el perfeccionamiento de la palabra periodística, a fin de que -manteniendo sus rasgos de identidad-literatura y periodismo pueden seguir aportando mutuamente sus saberes hacia una comunicación social de mayor calidad tanto ética como fornal.
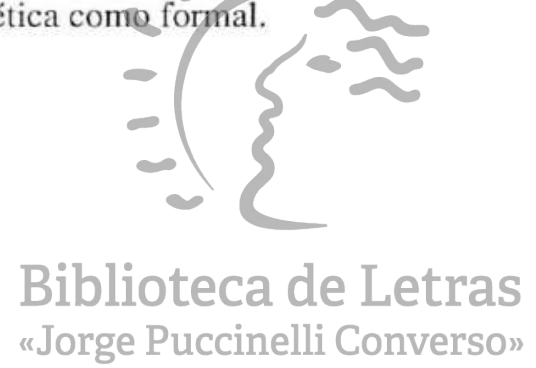